\title{
J
}

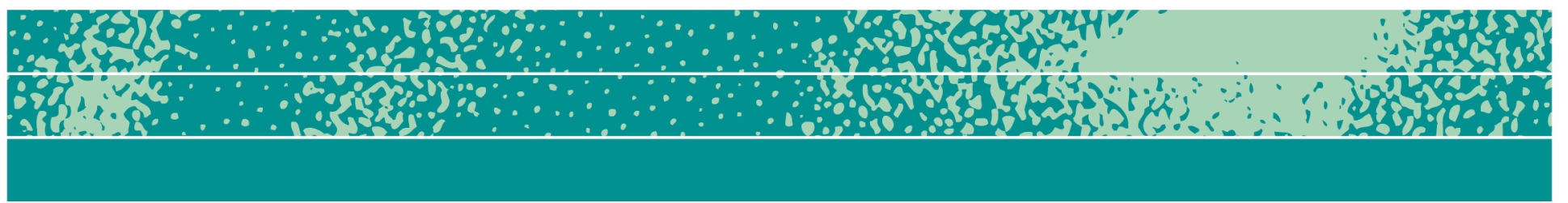

\section{Erasmus Syllogisms in Cognition and Facilitation of Organizational Innovation}

Rolf J. Bye and Stein E. Johansen

\begin{abstract}
By use of an empirical example from a planned organizational change program within an international company, we examine how specific characteristics of objects (forms) used to represent ideas - in interaction with "hard-wired" aspects of human cognition - may contribute to explain outcomes of translation processes and the extent of alteration of the design of the future organization. We argue that a type of syllogism judged as invalid by criteria of formal logics - denoted as Erasmus syllogism - could be rather common in reasoning, and that these logically invalid interferences may contribute to significant innovations. Situations where syllogisms are not recognized as invalid by the involved actors seem to be more prevalent when e.g. the actors are unfamiliar with the semantic content (as e.g. abstract symbols). We argue that understanding of semiotic conditions for occurrence of formal logically invalid syllogism, as well as of the neglect of their invalidity by involved actors in ongoing discourses and reasoning, may contribute to a better understanding of how ideas and objects are translated, within organizations as well as in general. The discussion is a contribution to better understanding of why and how ideas are altered as part of ongoing sense making processes within organizations.
\end{abstract}

Page 1 of 28

JBA 9(1): 111-138

Spring 2020

(C) The Author(s) 2020

ISSN 2245-4217

DOI:

10.22439/iba.v9i1.59

$\underline{\underline{64}}$ 


\section{Key words}

New Institutionalism, Erasmus syllogism, translations, cognition, semiotics

\section{Introduction}

For some decades, the study of how normative management theories are developed and shared within and between organizations has been a research topic within organizational studies. Two important concepts applied in these studies have been translations and boundary objects. Use of the concept "translation" is often associated with what has become known as the Scandinavian branch of new institutionalism (see e.g. Czarniawska and Joerges 1996; Czarniawska 2001; Czarniawska and Sevón 2005; Røvik 2002, 2011). In contrast to the classical works on management theories, which argued that organizations are becoming increasingly more alike structurally (Meyer and Rowan 1977; DiMaggio and Powell 1983), the later, new institutionalists have been focusing on how shared concepts are translated and sometimes altered when they are used within different organizations. According to Czarniawska and Sevon (2005) their main objective has been to study:

'....management ideas translated into objects (models, books, transparencies), sent to other places than those where they emerge, translated into new forms of objects, and then sometimes in actions, which, if repeated, might be stabilized into institutions through abstract ideas, which in turn could be described and summarized through abstract ideas and so in and so forth.' (Czarniawska and Sevon 2005:8).

The concept of translation has been among the main concepts used by Bruno Latour (1987) in his actor-network theory, denoting processes where objects are altered by humans through their interpretations and actions. Translation is related to diffusion, where the latter denotes the transfer or transmission of objects. Diffusion and translation are conceptualized as related to each other as Janus faces, i.e. as representing two contrasting and complementary aspects.

Alterations of objects and meaning have been explained e.g. as results of divergent interests of different actors and of how intentions (and power relations) are inscribed in the objects (cf. Latour 1987). Representatives of the Scandinavian new institutional perspective have proposed similar explanations. For example, Brunsson (1987) proposes that conflicts of interest and divergent ideologies may explain the alteration process leading to innovations. The potential for innovation is regarded as dependent on the pluralism of ideologies within an organization. 
Compared to actor-network theory the Scandinavian branch of new institutionalism has tended to be more oriented towards contextualized local interpretations. The alteration process of both objects and meaning is seen as a consequence of a variety of interpretations conducted by distributed actors making sense of objects by contextualizing the objects to local institutional traits (Røvik 2016). Processes of alteration through interpretations have been denoted as contextualization, recontextualization, re-embedding, etc. (Wæraas and Nielsen 2016). The quest has to some extent been to analyze how the translated concepts cohere to established practices and "world views" within an organization.

The Scandinavian new institutionalism has been criticized for regarding almost as an axiom that any translation process will result in a transformation, and not focusing much on the extent of alteration (Røvik 2016). In general, whether implicit or explicit, radical innovations have mainly been explained as a consequence of the degree of differences in institutional features. It has been argued (see e.g. Lundberg and Sataøen 2014) that studies of the processing of organizational concepts within organizations mainly have been oriented towards the introductions of metaphors, such as e.g. 'virus', 'mutations', 'immunity', 'incubation' etc. (see e.g. Røvik 2011) used to denote categories for classifying different types of alterations and translation processes, not to explain how such processing occurs.

Even though the incorporation of cognitive theory is considered as the hallmark that distinguishes new institutionalism from traditional institutionalism by the use of concepts such as, e.g. schema and scripts (see e.g. Scott 1995), the Scandinavian traditions do not seem to rely that profoundly on cognitive theories in order to explain the actual, observed translation processes.

The concept of boundary objects has been used in order to analyze organizational learning processes and how organizational features change due to ongoing interactions (Wenger 1998). Wenger operates with a strict distinction between forms ("objects") and meaning. Forms are physical artifacts that individuals use to express meaning, i.e. "objects" that may be shared and compared, such as e.g., instruction manuals, posters, tools etc. Meaning is related to these objects by the organizational members through interaction. This conceptualization makes it reasonable to assume that differences in form may imply differences in meaning, but also that resemblances in form do not necessarily imply resemblances in terms of meaning. Wenger (1998) uses the concept of boundary objects, originally developed by Star (1988) and Star and Griesemer (1989), to denote artifacts, documents, terms, concepts, and other forms of reification that are distributed and shared among communities, which in turn make sense out of them and act towards them by relating them to local symbols and belonging meanings. 
In her paper 'This is Not a Boundary Object: Reflections on the origin of the concept', Star argues that this concept introduced by her has been often used by researchers to address 'interpretive flexibility', i.e. how different actors through ongoing discourses interpret and attribute different meanings to objects (Star 2010,614). Star criticizes this use, by claiming that this use of the concept implies nothing more than following the 'constructivist' approach within social science, i.e. the perspective that different social systems construct different meanings. Star claims that one important aspect of boundary objects is their differences in terms of 'material/organizational structure' and how these differences matter with regard to how people are able to act towards and with the object.

In this article we will argue that translation processes and their possible outcomes should not be understood and analyzed only as discursive activity conducted by specific social groups with belonging socially constructed and institutionalized conventions. We will argue that the forms of the objects that represent meaning, in interplay with more hard-wired aspects of human cognitive capacities, are crucial for the actual outcome of the translation process.

These aspects are viewed as important in order to understand alterations of both objects and meaning. We demonstrate how people are inclined to commit one type of logical fallacies, denoted as Erasmus syllogisms, when not being supported by adequate semantic content, and that such error in purely logical reasoning may contribute constructively to significant alterations and innovations.

The remainder of this paper consists of our 1) case description of a planned change process in an international company and the merger of two different change initiatives; 2) formal analysis of the cognitive coupling between the two change initiatives; 3 ) discussion regarding logic vs. semantics in cognition; and 4) conclusion.

\section{Case: Processual Change Project in an International Oil and Gas Company}

Our empirical example is picked from an international oil and gas company where two different planned organizational change programs were merged. The case description is based on a finding during a longitudinal fieldwork within the company between the autumn of 1997 and the spring of 2002 (Bye 2010). The objective of this research was to study organizational learning processes during a comprehensive planned change project, involving all subsidiaries.

Methods used to obtain data during the fieldwork included surveys, semi-structured interviews, open ethnographic interviews, participatory observation, and studies of documents (reports, design descriptions and artefacts as work process charts, e-posts, letters, 
informal drawings, logos etc.). The fieldwork was multi-sited within the organization and took place over a period of five years. In the beginning of the research project, fieldwork was conducted in the project organization responsible for designing the new organizational concept during a period of 18 months. In addition, the researcher took part in meetings between representatives from the project organization and the local subsidiaries. Later, a six-month period of fieldwork was conducted in implementation projects at one onshore process plant and at an offshore installation after the new organizational model had been implemented. The research method was predominantly based on participant observation, where the researcher worked as a secretary in the project organization.

During the next three years, several shorter fieldworks (3-14 days) were conducted within four different subsidiaries in the aftermath of the local implementation processes. This research was predominantly based on ethnographic interviews and semi-structured interviews, combined with use of shadowing (Czarniawska 2007) and participatory transects (Chambers 2006) as observation techniques.

Two surveys were conducted during the research period in order to measure perceptions of and attitudes towards the new organizational concept, and the results of the following analysis (descriptive statistics) were used to support the interpretation of the qualitative data.

One of the change initiatives within the company was denoted $B O I$ ('Best Operator in the Industry'), and the other was denoted BFA ('Better and Faster Administration'. (In the context of the present article, we have translated from the local language into English the names of the change initiatives and their acronyms.)

BOI had been initiated several years before BFA and was a change initiative that emerged as part of a rather harsh conflict between trade unions and managers in one of the company's divisions. BOI was initiated as a measure proceeding from a work environment survey that showed very low confidence in the management. This low confidence level was sought and explained as a consequence of negative experiences from several improvement programs preceding the survey. In order to improve the relation between managers and employees, there was established a work group consisting of representatives from both the trade union and from the management. Its mandate was to "describe the future organization". The work of the group was facilitated by an external researcher in organizational studies, belonging to the socio-technical tradition of organizational development (see e.g. Trist 1976, Emery and Thorsrud 1976) and inspired by the theory of Total Quality Management (TQM) (Deming 1982, Deming and Edwards 1982). In this tradition, as well as in this theory, key concepts used in representation of the future organization are 'self-managing teams' (see e.g. Hackman 1986) and 'integrated teams' (Herbst 1976). The concept of self-managing teams has 
been used in normative socio-technical theory and emphasizes organization of workers into teams where they themselves make the necessary decisions in relation to a particular production process (see, e.g., Manz 1992).

The concept of integrated teams has been used in the literature to denote an organizational form intended to promote collaboration and effective problem solving in operational activities by co-organizing multidisciplinary professionals (e.g. process technicians, mechanics, electricians etc.) who take care of various functions in the particular operation. Here, the employees handle the problem solving activity themselves without relying on a hierarchical decision system. 'Integrated teams' has been conceptualized as an organizational form that represents an alternative to function-based hierarchical organization. The Japanese improvement system denoted as Kaizen teian ('improvement suggestions' has been considered an important "tool" within the TQM literature (see, e.g., Gondhalekar, Subash Babu and Godrej 1995). Kaizen teian denotes a team-based system for generating and implementing ideas from employees. Kaizen teian is sometimes associated with Kaizen teams, i.e., 'improvement teams' (see e.g. Suárez-Barraza and Lingham 2008).

Common for these three concepts; self-managing teams, integrated teams, and Kaizen teian; is that they emphasize employee involvement as an instrumental measure. However, descriptions of the objectives for these three concepts have been somewhat different. The objective of self-managing teams has been conceptualized as a contribution to democratization and counter alienation among workers in a particular production process, and at the same time to improve the productivity. The objective of integrated teams has been conceptualized as improved ability to solve more complex and unforeseen problems by combining the skills and knowledge of the different team members, and at the same time to reduce the need for a hierarchical decision system. The objective of improvement teams has been conceptualized in TQM as ensuring that personnel with direct experience of manufacturing processes use their knowledge to improve the organization. All three concepts were used as references in the representation of BOI, merging them together and preferring 'integrated teams' as an umbrella term. If we look into the three terms themselves, they all include the term "teams". Further, the referents to all three terms seem to address a kind of employee involvement. The term "integrated teams" was already a rather familiar term within the organization, having been applied in various documentation, and with this concept being used in the development of one of the subsidaries. It seems reasonable that the combination of familiarity with this term, the partial similarity of form, and partial coherence between the references to the three terms, may account for the merging process.

The other change initiative, BFA, was a planned organizational 
change project with the objective to standardize the way of doing administrative work, conceptualized as work processes, throughout the organization. The standardization was supposed to reduce costs by reconfiguring the steps in which work is done, as well as the responsibilities to perform implied tasks. The change program was inspired by Business Process Reengineering (BPR) theories for organizational change (Hammer 1990; Hammer and Champy 1993; Davenport 1993; Hammer 1996). BPR were among those normative improvement theories and methods that were most popular in management communities during the 1990s.

A core idea of this method was to combine new information technology with human tasks in order to change the production process. This should not be done by automating existing work processes, but instead by combining new technology and tasks performed by people in a 'new way' (Hammer 1990). Davenport $(1993,5)$ defines process as 'a structured, measured set of activities designed to produce a specified output for a particular customer or market,' where the activities may be conducted by a machine or by humans. By re-designing work processes, it is argued that it is possible to make radical changes in the organization which will result in a leap in productivity. This method is contrasted to e.g., TQM which has been criticized for just providing limited improvement, step by step, based on existing work processes:

'Nor is reengineering the same as quality improvement, total quality management (TQM), or any other manifestation of the contemporary quality movement [quality programs works within the framework of the company's existing processes and seek to enhance them by means of what Japanese call kaizen, or continuous incremental improvement.] (...) Reengineering, as we have seen, seek breakthroughs, not by enhancing existing processes, but by discarding them and replacing them with entirely new ones.' (Hammer and Champy 1993, 49).

An important concept within the reengineering tradition has been to 'reuse' human and activities through interaction with the IT system. For example, ordering a spare part through the logistic system may also be included as information in, e.g., the accounting systems and financial processes.

The information system that was used in the BFA project was $S A P$, which at that time was denoted as an ERP system (Enterprise Resource Planning). SAP is an IT program that serves the totality of business activities in a company (e.g., sales, production planning, logistics, human resources, accountancy, finances etc.) and where it is possible to link information related to the different business activities.

Several of the reengineering theorists argue that one should focus on designing the work process, not on how people should be organized 
and managed within the organization. However, some organizational features are assumed to be consequences of the reengineering initiatives. For example, Hammer and Champy state that 'work units change - from functional departments to process teams,' (Hammer and Champy 1993, 65) that 'people's roles change - from controlled to empowered' (ibid, 70), and argue that 'empowerment is an unavoidable consequence of reengineered processes; processes can't be reengineered without empowering process workers' (ibid, 71). They argue that new effective work processes require more judgment rather than compliance with clearly defined rules and manual tasks. Thus, workers must be able to make the decisions that new processes require. In addition to allowing new and more efficient processes, it is also expected that such novel work processes will increase workers' job motivation.

Another recommended change in the formal organization from reengineering was that 'managers change-from supervisors to coaches' (ibid, 76). Managers were not supposed to control and make decisions on behalf of the employees, but rather to coach them and develop their skills in order to improve their ability to perform their tasks. The concept of 'empowerment' has been discussed within the community of organizational studies, and has been contrasted to 'employee involvement' emphasized in socio-technological normative theories. According to, e.g., Greenwood and Lewin (1998) 'empowerment' shall be considered as a means to increase productivity, not to be based on a democratic ideal and an objective of increased job satisfaction.

The design of the organization should, according to BPR theorists, be conducted by dedicated "re-engineering teams" with responsibility for designing processes by combining performances by humans and by information technology. The ideal for the design work was to be freed from 'knowledge of the past' and start with 'blank sheets'.

Implementations of new work processes should be based on a centralized management, applying measurable indicators and incentive systems in order to change the actions performed by the employees.

The initiative of BFA originated from top managements, while concept description and programming were conducted by a project team with members recruited from different divisions and departments within the corporations as well as from consultants from several international consulting firms. During a design period of 12 months different groups developed representations of the imagined new organization by use of different artefacts such as documents, transparencies, charts, e-learning programs, etc. In order to denote and represent rather complex entities, their images were 'chunked' into new abstract concepts as a part of the ongoing discourse.

Implementation of the design of the new future organization turned out to be difficult. Both managers and employees within different 
divisions expressed resistance to the new concept. The opposition was especially apparent from one of the company's divisions, which had not been much involved in the development process. The plans for the new organization was criticized for, e.g., lack of knowledge about development and production, lack of humility towards existing practices, and lack of involvement of the offshore organization. Representatives from this division, from now on referred to by us as the development division, pointed out that BOI was the change program that they were going to realize, not BFA. During these discussions BOI were to some extent revitalized, from merely being a stored document describing a future organization, to something that should be implemented.

The lack of support for the BFA initiative was met with new initiatives from representatives of the BFA project. Among these was the establishment of a new project team with the mandate to adjust the BFA model by integrating experience-based knowledge from the development division. The new project team consisted of representatives from the original BFA organization as well as of representatives from the development division, familiar with the BOI concept. During the ongoing re-design and re-representation of the new organization, terms and concepts as 'self-managing teams', 'integrated teams', 'improvement teams', and 'process teams' were used as references. In this discourse some of the representatives from the original BFA organization stressed and promoted that BFA should be a 'quantum leap' in accordance with BPR theory and based on one standardized model, not a gradual improvement process with the danger of local adaptations and variations. In contrast to this, representatives from the development division emphasized that 'people had to be involved' and should 'recognize their established practice and familiarity with continuous improvement processes'.

During this process some claimed that there was a similarity between BOI and BFA, represented by the use of 'integrated teams' as a concept. During the ongoing discourse, 'integrated teams' became reconceptualized as 'multidisciplinary teams', 'empowered' to manage and make decisions according to the designed "work processes". Different 'integrated teams' were going to be responsible for specified areas or parts of the production system. These teams were designed as independent organizational units, defined as cost centres (units where cost related to e.g. work hours, equipment and spare parts are allocated through the IT-system). The managers should support the teams, serving more as 'coaches' rather than acting as decision makers. During the design process, representatives from the BFA organization was concerned that the concept of 'integrated teams' would be mixed with the concept of 'self-managing teams', underlining that 'they were not the same'. They argued that decisions taken by the teams should be those defined by the work processes, not by the organization of the teams themselves. As part 
of this re-design of BFA new representations were developed in order to communicate with the rest of the organization. Among these representations, the following formula was used in the communication between the BFA organization and the development division:

$$
\mathrm{BFA}=\mathrm{BOI}+\mathrm{SAP}
$$

The coupling between BOI and BFA was legitimized by claiming that both descriptions of a future organization used 'integrated team' as a concept. From this it was argued that BFA was partly the same as BOI. The main difference between the models was explained to be that BFA included the use of the SAP information system.

In the first and prototypic implementation project within the subsidiary, which was supposed to become the model for the others, much attention was directed towards implementation of integrated teams, and towards distribution of responsibilities among the team members. Themes present in the original BOI design became represented in the local discourse among both managers and employees, and concerns about self-management of the teams were focused among the main issues.

The plant was divided into areas with attached multidisciplinary teams (consisting of, e.g., process technicians, automation technicians, mechanics, electricians, crane operators). In order to ensure performance of tasks related to human resources, procurement, and economy within each team, ascribed roles denoted as 'coordinators' were invented. These roles were organized temporarily and based on rotation between team members. Further, novel roles of coordination became invented, in order to achieve dedicated responsibility of administrative tasks related to coordination of team members' activities, financial management and control of the teams, and the responsibility to follow up Health, Safety and Environment (HSE) related activities within the teams. This organizational design was supposed to constitute self-sufficient teams, capable of managing themselves. Managers in the previous hierarchical and function- based organization became re-organized into a "management team" that should supervise and advise the other teams, based on ongoing evaluations of the teams' decisions and performances.

The most apparent consequence during the implementation of the new organizational form in the subsidiaries was the focus on establishing successful "integrated teams". This somewhat conceptual implementation became a priority, while the changes in work processes gained less attention. The focus on integrational teams tended to "overshadow" other aspects of BFA design, and contributed to implementation of rather innovative solutions for how the teams should manage their daily work. 


\section{Formal Analysis of the Cognitive Coupling Between BOI and BFA}

If we look more closely at the formula BFA=BOI+SAP and the justification for this representation, the implicit reasoning may be represented by the following formal categorical syllogism which we denote the $B F A$ -

syllogism:

BOI has 'integrated teams'

\section{$\underline{B F A}$ has 'integrated teams' and SAP}

Therefore, BFA is BOI with SAP

Before contemplating this syllogism further, let us first as reference take a look at a simple syllogism of the form:

$\mathrm{P}_{1}: a$ is $c$

$\underline{\mathrm{P}_{2}}: \underline{b \text { is } a}$

C: $b$ is $c$

Here the expressions $\mathrm{P}_{1}$ and $\mathrm{P}_{2}$ represent two premises, from which the expression $C$ is implied as conclusion with logical necessity. This reads as: IF [ $a$ is $c]$ AND [ $b$ is $a]$; THEN $[b$ is $c]$. As an illustration, denote 'all apes' with $a$; 'all gorillas' with $b$; and 'all animals' with $c$. Then the syllogism reads as: IF [all apes are animals] AND [all gorillas are apes]; THEN [all gorillas are animals]. This reference syllogism is always true due to the classification hierarchy represented by the terms $a, b$ and c.

Let us next consider a syllogism of the following form:

$\mathrm{P}_{1}: a$ is $c$

$\underline{\mathrm{P}_{2}}: \underline{b \text { is } c}$

$\mathrm{C}: b$ is $a$

We name this form the Erasmus syllogism, inspired by the notorious argument flung out by the character Erasmus in Ludvig Holberg's Norwegian comedy Erasmus Montanus_(1967) [1723]: 'A rock cannot fly; Mother Nille cannot fly; ergo, Mother Nille is a rock', where after Mother Nille bursts into crying. We may denote 'a rock' with $a$; "Mother Nille" with $b$; and 'not capable of flying' with $c$. Then the syllogism reads as: IF [a rock is not capable of flying] AND [Mother Nille is not capable of flying]; THEN [Mother Nille is a rock]. Trivially, the Erasmus syllogism is invalid by the criteria of formal logic, contrary to a valid syllogism as the reference syllogism above. 
Next we consider the following syllogism:

$\mathrm{P}_{1}: a$ is $c$

$\mathrm{P}_{2}: b$ is $c$

$\underline{\mathrm{P}}_{3}: \underline{b \text { is } d}$

C: $(b$ is $a) \&(b$ is $d)$

The second joint and sub-expression in the conclusion, ( $b$ is $d$ ), is identical to premise $\mathrm{P}_{3}$ and hence this sub-expression is trivially implicated from $\mathrm{P}_{3} . \mathrm{P}_{3}$ is irrelevant for the truth of the first sub-expression in the conclusion, ( $b$ is $a$ ). Consequently, the possible truth of ( $b$ is $a$ ), as well as the possible truth of the conclusion as a whole, depends solely on the inference from premises $\mathrm{P}_{1}$ and $\mathrm{P}_{2}$ being valid. Thus, in order to judge the logical validity of the syllogism as a whole, we can remove $\mathrm{P}_{3}$ from the three premises, as well as the sub-expression ( $b$ is $d$ ) from the conclusion. The remaining syllogism then becomes identical to the Erasmus syllogism, and therefore invalid. This means that the syllogism as a whole is just a prolonged version of the Erasmus syllogism in its simplest expression, and is generally invalid by exactly the same criteria of formal logics. Due to the logically irrelevant addition of ( $b$ is $d$ ) to premises $\mathrm{P}_{1}$ and $\mathrm{P}_{2}$, as well as to the conclusion, we name this prolonged version of the Erasmus syllogism a dead weighted Erasmus syllogism.

As an illustration of a dead weighted Erasmus syllogism, we denote "a human" with $a$; 'a seagull' with $b$; 'an organism having two feet' with $c$; and 'an organism having a beak' with $d$. Then the syllogism reads as: IF [a human is an organism with two feet] AND [a seagull is an organism having two feet] AND [a seagull is an organism having a beak]; THEN [a seagull is a human] AND [a seagull is an organism having a beak].

We may re-express the logical structure of this syllogism by redressing it in more daily day language, combining $\mathrm{P}_{2}$ and $\mathrm{P}_{3}$ into one prolonged second premise, and compressing the linguistic expression of the conclusion:

A human has two feet

A seagull has two feet and a beak

Therefore, a seagull is a human with a beak

We realize that the logical structure of this syllogism is identical to the logical structure of the BFA-syllogism which we may repeat for inconspicuous comparison:

BOI has 'integrated teams'

BFA has 'integrated teams' and SAP

Therefore, BFA is BOI with SAP

Thus, we also realize that the BFA-syllogism represents a dead 
weighted Erasmus syllogism, and is invalid by criteria of formal logics for exactly the same reasons that Erasmus syllogisms in general are invalid. In the applied illustration involving a human and a seagull, the logical fallacy of the dead weighted Erasmus syllogism appears obvious due to the concise familiarity with the involved words signifying the logical terms and the involved semantic relations signifying the logical relations. In spite of the logical identity between the human/seagull syllogism and the BFA-syllogism, in the last case the logical fallacy appears less obvious to minds who lack skills in logical reasoning sharp as a razor blade. More generally, what is more or less involved here, are operators in cognition, with accompanying brain architecture, working towards conflation and confusion of cognitive entities residing at the ontological level of structural logics with cognitive entities residing at the ontological level of semantic representation (or pre-representation) of structural logics.

Also, the very prolongation of the involved Erasmus syllogism into a dead weighted Erasmus syllogism, may work to amplify the impact from said operators in cognition working towards conflation and confusion. This is easily exposed by removing the logically irrelevant premise $\mathrm{P}_{3}$, duplicated as the second sub-expression of the conclusion, from the universal and elementary form of the dead weighted Erasmus syllogism. When redressed into daily day language such removal results in the following expressions of the human/seagull syllogism vs. the BFAsyllogism:

A human has two feet

A seagull has two feet

Therefore, a seagull is a human

BOI has 'integrated teams'

BFA has 'integrated teams'

Therefore, BFA is BOI

With respect to the human/seagull syllogism this reformulation into the naked Erasmus syllogism is not likely to make any difference at all towards judging the syllogism as invalid. However, with respect to the BFA-syllogism, applying less familiar and concise words in representation of the logical structure, this reformulation is likely to make quite some difference in several minds for the cognition of the logical structure. It is hard to imagine anyone involved acknowledging this stripped version of the BFA-syllogism as logically valid (and gaining motivational impetus from such validity). On the other hand, it is not that hard to imagine several persons being involved, as believing in the logical validity of the prolonged, dead weighted version of the BFA-syllogism, and perhaps even become motivated for changes in the company from such a logically false 
belief. Since the logical structure of the naked Erasmus syllogism is exactly the same as the logical structure of the prolonged, dead weighted Erasmus syllogism, also in the case of the semantics provided by the BFAsyllogism, this appears as a rather interesting paradox.

This seems to suggest that the very prolongation of the Erasmus syllogism, into its dead weighted version, works more or less towards amplifying significant conflation and confusion between ontological levels of structural logics vs. levels of semantics, via operators of complexification, and that the resulting impact in some cases, as the present one, would not be likely to occur without said prolongation and complexification.

Further, one may also argue that the BFA-syllogism covers a certain equivocation, which works towards a fallacy of four terms (quaternio terminorum). The term 'integrated teams' may denote two rather different meanings, and for this reason the term cannot be adequately conceived as that of a strict and concise concept, but rather as a homonym. In the BFA design, the referent of 'integrated teams' was a notion of a group of employees with different professions and competence who had become 'empowered' to accomplish a set of defined decisions in specified situations. The main objective, according to this meaning of the term, was to improve efficiency and production flow. In BOI, however, 'integrated teams' denoted a notion of groups of employees that cooperate, plan and make decisions regarding their daily work, rather autonomously and more extended than in the BFA design. In this interpretation of the term, involvement in decision processes was not limited to a set of tasks related to the established work processes, but included also involvement in strategical decisions regarding, e.g., how the work should be organized with according proper allocation of resources. A main objective of this meaning of the term 'integrating teams' was to increase the well-being of the workers and to counteract alienation.

The formula of the BFA-syllogism, BFA=BOI+SAP, worked as a crucial category in the ongoing discourse forerunning and promoting implementation of BFA, despite the logical fallacy of the related Erasmus syllogism. In interactions during anthropological field work in the company, involved actors did not question the validity of the formula, nor did they address any logical issues connected to the formula.

As a matter of fact, the use of the formula in communications between the project organization and the rest of the corporation, contributed to alteration of representation and implementation of BFA. By more intimate linking of BOI and BFA, promoted by the Erasmus syllogism, other representations and aspects associated with BOI, not included in the BFA-syllogism, became included in novel representations of BFA. This did result in various organizational implementations and innovations, based on the merge of concepts implied in BOI and BFA 
design, i.e. on emerging conceptions that were not present in the original BFA design. Among others, such innovations included the implemented notion of comprehensive self-management of the teams, and the crucial role attributed to the novel notion of coordinators.

\section{Logical Reasoning and Decision Making}

Limitation in terms of logical reasoning and rational decision-making has been a topic in organization studies for decades. Within the field of decision theory, the concept of "bounded rationality", coined by Herbert Simon (1957), captures the idea that rationality of individuals is limited due to their available information, cognitive limitations of their minds, and limitation of time for making decisions.

James March (1994) argues that decisions may primarily be about completely different matters rather than the explicit problems and solutions being addressed. According to March decision-making processes in an organization can also be about positions, legitimacy, trust, etc. This perspective corresponds to Brunsson's (1989) formulation of "hypocrisy talk", in an attempt to describe a perceived discrepancy between how leaders represent their organization and how they actually act. Such discrepancies are explained as a consequence of e.g. reputational aspects ("dynamic", "active", "up to date," etc.) rather than the stated objectives of a decision.

Within the "The Garbage Can Model" of Cohen et al. (1972) problems, solutions and decision makers are treated as decoupled from each other in terms of meaning. Decision situations (denoted as "garbage cans") are treated as a kind of algorithm that links problems and solutions. This results in an available repertoire of solutions that can be used as a response to different problems. March (1994) points out that only a limited number of solutions are considered sequentially and individually, rather than simultaneously, and that it is possible to associate each solution with a plurality of problems, provided they coincide in time.

The research of Kahneman, Tversky and Slovic has contributed to the understanding of cognitive biases of individuals when making decisions (Kahneman et al. 1982). Kahneman has developed the concept of heuristics in order to denote simple strategies and cognitive processes that are applied to quickly perform judgements, make decisions and find solutions to complex problems (Kahneman et al. 1982). Based on a wide range of experiments, a number of different logical fallacies have been identified. One example is the so-called conjunction fallacy, which is also known as the Linda problem. This logical fallacy occurs when it is assumed that specific conditions are more probable than a single general one. In the experiments the participants were given a description about Linda, a 31-year old, single, outspoken, and very bright woman with a 
major in philosophy. Further, the respondents were informed that as a student, she was deeply concerned with issues of discrimination and social justice, and also participated in anti-nuclear demonstrations. Then the test persons were asked to assess the likelihood of different statements about Linda. The majority of the test persons tended to consider the statements more likely to be true, if the statements were more comprehensive. For instance, they tended to rate the statement "Linda is a bank teller and is active in the feminist movement" as more likely than the statement that just claimed that "Linda is a bank teller", although the probability of the two characteristics (bank teller and feminist) to be true, is less than the single characteristic (just being a bank teller). The fallacy is explained as a consequence of people considering "feminist" as more representative for the person Linda than "bank teller". Tversky and Kahneman $(1982,1983)$ consider the conjunction fallacy as a consequence of a cognitive process denoted as the representativeness heuristic. This heuristic implies that people may perform logically biased judgements based on how high representativeness an attribute has as compared with the prototypic attribute of a category.

More generally regarded, one significant finding from tests of skills in logical reasoning carried out by cognitive science, is that, for most humans, the semantic content of a syllogism highly influences the chance for being able to perform a logically correct deduction, despite that the semantic content is irrelevant for the logical form of the syllogism. Interestingly, such influence also occurs in test situations where subjects are instructed to not look at the semantic content but to solely consider the logical structure.

Some early tests triggered the so-called Wason problem challenged to explain the empirical fact that the success rate to perform a certain deduction exposed an immense variation (between $20 \%$ and $70 \%$ !) among American undergraduates, dependent on the semantic dressing of the identical structural logic (cf. Wason 1968).

D'Andrade $(1989,1992,1995)$ presented a pioneering work establishing cognitive anthropology as a novel (sub-)discipline, congruent with and inspired by many results from cognitive science as well as by certain anthropological studies and theories. Besides his overwhelmingly theoretical contribution, building on empirical results and ethnographic works by others, relevant for cognitive anthropology, D'Andrade also designed and carried out interesting tests among American college students in order to map and contemplate influences from semantic content which disturbed cognitive abilities to perform logically correct deductions (cf. D'Andrade 1995, 203, table 8.2, with related discussion). His tests involved three different kinds of deductions, when varying the degree of 'realistic content' vs. 'arbitrary content' in the semantic dressing of these three deductions. In the present context we will only contemplate 
two of these three kinds of deductions, namely modus ponens (IF $\mathrm{P}_{1}$ : if $p$ then $q$, AND $\mathrm{P}_{2}$ : $p$; THEN C: $q$ ), and modus tollens (IF $\mathrm{P}_{1}$ : if $p$ then $q$, AND $\mathrm{P}_{2}$ : not $q$; THEN C: $\operatorname{not} p$ ).

Some main results of his tests were: With respect to modus ponens the success rate of being able to perform a correct deduction varied between $96 \%$ and $80 \%$, decreasing with 'arbitrary content' relatively to 'realistic content' With respect to modus tollens the rate of success varied between $96 \%$ and $33 \%$, decreasing much more radically, as compared to modus ponens, with increase in "arbitrary content" relatively to the logical reasoning being supported semantically by "realistic content".

Interestingly, the lowest correct score with respect to modus tollens, i.e., 33\% (!), manifested from semantic dressing of the syllogism as: 'IF [J is true, then $\mathrm{K}$ is true] AND [not-K is true], THEN ...'. (The dots '...'represent three alternatives for an answer; cf. D'Andrade 1989.) The third lowest score (among 13 variations of semantic dressing), i.e., 45\%, manifested from the semantic dressing of the modus tollens syllogism as: "IF [D is true, then E is true] AND [E is false], THEN ...".

A rather obvious interpretation of the test results referred in the last paragraph, is that the very act of abstraction from any semantic dressing, tended strongly to make it even more difficult for most test subjects to perform a correct deduction of modus tollens, as compared to when the syllogism was dressed in more familiar words from daily day language, even when such familiar semantics were highly 'arbitrary' or even rather nonsensical, relatively to "realistic". These test results may appear highly surprising for gifted minds or those skilled in formal disciplines as mathematics, logics and informatics, minds that in most cases will perform deductions with more ease when the semantic dressing has become stripped and abstracted. Nevertheless, it is interesting to acknowledge that cognition works differently in most minds, and it is not likely that the sample involved in the tests by D'Andrade possessed an average IQ below 100 .

Despite that generalization from one sample to others should be associated with some caution, these test results seem to be of some special interest with respect to contemplating the impact or seduction from the BFA-syllogism. Said test results suggest, other things equal, that semantic dressing involving symbols of high abstraction makes it more difficult for most humans to perform logical reasoning and to become most seriously disturbed in their logical reasoning from this semantic dressing of the involved syllogisms. This, rather paradoxically, being so in spite of the obvious fact that such abstractions are crucial and necessary in more or less formal disciplines of science. (The difference between the $33 \%$ case and the $45 \%$ case may be explained by that cognitive recognition of the negation involved in the second premise expressed as [not-K is true] will involve a bit more cognitive effort than the expression 
[E is false], despite their logical identity. This difference may be of some more general interest as suggesting that apparently minor differences between decisive thresholds in cognitive efforts may be rather crucial in order to make a difference for performing correct logical reasoning. Thus, said difference confirms and extends the more striking difference between the two thresholds in cognitive efforts being able to perform modus tollens vs. modus ponens.)

One of us (Johansen) carried out a simple test on novel master students in social anthropology at Norwegian University of Science and Technology, in order to indicate skills in logical reasoning and to illustrate significance of cognitive anthropology. The same test was repeated for three cohorts of students (Fall 2013, Fall 2014, Fall 2015), involving a total sample of 38 students. During the 15 minute break between two lectures in cognitive anthropology the students would anonymously answer a questionnaire consisting of three questions, choosing among three alternative answers where one and only one represented a correct logical deduction. Achieving a correct answer to questions no. I and II required a modus tollens deduction, and achieving a correct answer to question no. III required a modus ponens deduction. The semantic content of syllogism II was chosen to be familiar and realistic, while the semantic content of syllogism I was chosen to be familiar while only moderately realistic. The prediction was that more students would perform a correct deduction of syllogism II than of syllogism I, despite the logical structure of modus tollens being exactly the same and the students being instructed before the test that they should only consider the logical connection between premises and conclusion, not the realism of the semantic content. Among the total sample of 38 students, 29 students answered question II correctly, while only 16 students answered question I correctly, thus strongly confirming the prediction. Syllogism III had identical semantic content as syllogism I, thus chosen to be familiar while only moderately realistic, so that the difference between syllogisms I and III was solely due to the formal difference between modus ponens and modus tollens. The prediction was that more students would perform a correct deduction of syllogism III than I, due to modus tollens being more cognitively demanding to perform than modus ponens. 29 students answered question III correctly, a rather striking difference to the 16 students answering question I correctly. 12 students answered all three questions correctly, while 2 students gave wrong answers to all three questions. With respect to over-all performance in logical reasoning, there did not occur any striking difference between the three cohorts of students.

These test results were in good agreement with the results of the referred, similar and more extended tests carried out by D'Andrade, thus providing further support to the significance of semantic content for most humans being able to perform correct logical reasoning. 
From experimental evidence it appears as an empirical fact that most humans, even among those above average intelligence, are not able to perform correct logical deductions without their logical reasoning being supported by adequate semantic content, as soon as the involved deductions are a bit more complex than modus ponens.

D'Andrade $(1995,203-217)$ presents an informed discussion in order to account theoretically for such empirical facts demonstrated by experiments of cognitive science. He addresses the constraint represented by two forms of abstraction (ibid., 207) from content to form being difficult for most humans to perform. More generally he argues that logical reasoning is highly dependent on the reasoning subject being equipped with a cultural schema (ibid., 205) of semantic content in order to adequately access and implement the structural logic into successful performance of logical reasoning. The concept of "schema" can be traced at least back to Kant referring to the schema of, e.g., a dog as a pattern in the mind being able to recognize a dog as a dog despite that this pattern of a dog does not have any unique concrete manifestation.

Kant's notion of schema is consistent with much theory and experiments from modern cognitive science. In prototype theory, initiated by E. Rosch, cf. especially Rosch (1983) with respect to the present discussion, the prototype of, e.g. a bird, is regarded as a cognitive ideal type where no concrete bird will match this pattern completely. Various kinds of birds will match this ideal type in different degrees (with modest individual and cultural variation), so that some birds will be conceived as more birds than others. Classification of whether an animal is conceived as a bird at all, stretches out from the prototype, so that binary cognition is constituted by analog representation extending from the prototype. Typically, the border zone for classification will appear somewhat fuzzy. For zoologists a penguin is classified as a bird, while for many respondents this will not be the case, due to the penguin lacking the attribute of being able to fly, an attribute that is crucial in their implied prototype of 'bird' in their cognitive category.

Let us contemplate the following two syllogisms:

$\mathrm{P}_{1}$ : If the penguin is a bird, then the penguin can fly

$\underline{\mathrm{P}}_{2}$ : The penguin cannot fly

C: The penguin is not a bird

$\mathrm{P}_{1}$ : If the penguin cannot fly, the penguin is not a bird

$\underline{\mathrm{P}}_{2}:$ The penguin is a bird

C: The penguin can fly

If $p$ denotes [The penguin is a bird]; and $q$ denotes [The penguin can fly], the first syllogism has the form: IF $[p=>q]$ AND not- $q$, THEN not- 
$p$, i.e. the form of modus tollens.

The second syllogism has the form: IF [not- $q=>$ not- $p$ ] AND $p$, THEN $q$. If we substitute symbols $p$ and $q$ with symbols $r$ and $s$, defined as $r=$ not $-q$ and $s=$ not $-p$; this syllogism has the form IF $[r=>s]$ AND not-s, THEN not- $r$. This is the same form of modus tollens as the first syllogism, and it is disclosed that the two syllogisms are just two equivalent semantic expressions of the same logical relations.

Despite this equivalence it is rather obvious that the ability to successfully perform the two syllogisms will be different for many test subjects. While the first syllogism is not likely to be much demanding, although some zoologists may be a bit puzzled, the second syllogism is not likely to yield a high success rate.

The main reason for this difference is that the semantic content of the conclusion in the second syllogism for most test subjects will appear more radically different from their everyday notions and semantic cognition, so that their logical reasoning more easily will become disturbed by the feeling that there must be something wrong with the deduction.

Mandler $(1984,55)$ argues that 'activation of parts of a schema implies the activation of the whole, distinct from other structures and other schemas' (our italics). Such cognitive schemas develop from life experience, and are embedded in semantics and grammar of natural languages as well as in various cognitive operators residing in unconscious layers of the mind. Thus, logical reasoning is more difficult when semantic contents of logical expressions do not match preceding schemas becoming activated when processing such contents. Such lack of matching may be due to unfamiliarity with semantic content (as abstract symbols), lack of realism (as 'the penguin can fly'), or classification hierarchies in preceding schemas being in conflict with or too fuzzy to match the propositions involved in the logical expressions. On the other hand, when the matching is good between the semantic content in the logical expressions and well-formed preceding cognitive schemas, logical reasoning becomes facilitated.

Since Erasmus syllogisms are not logically valid, they represent a somewhat opposite case to syllogisms as modus ponens and modus tollens. Depending on semantic content expressing logical relations of form, with related activation of preceding cognitive schemas, Erasmus syllogisms may not seldom be conceived falsely as valid, for reasons analogous to those stimulating cognition of valid syllogisms as false.

With respect to sensory and neurological events involved in perception, overwhelming dominance of Erasmus syllogisms is a hardwired necessity. By means of fine-grained measurement apparatus, functioning as prolonged amplification of our senses, we can observe that the magnitude of two incoming stimuli, when sufficiently close as 
registered by our instruments, are not distinguished in response after entering the skin of an organism. This means that two different stimuli $a$ vs. $b$ are represented by the same quantity $c$ functioning as input for the next level of neurological processing inside the skin of the organism. This means that already reception, understood as the first and elementary act of perception, implies activations of Erasmus syllogisms. The neurological process constituting the first percept available for the conscious mind, involves, at least typically, certain input-output algorithms through six layers of the brain architecture (see, e.g., Churchland 1986 for basic details). These algorithms are based on traceless classifications (as distinguished from reflexive classifications); i.e., that such algorithms represented do not preserve a memory of the distinction between close input values after the algorithm has processed the two input values into the same output value. (Cf. foremost Johansen 2008, 41ff, and next Johansen 2018, 232-234, for definitions of these two concepts with related discussions to philosophy, informatics and neuroscience.) In general, traceless classification implies occurrence of Erasmus syllogisms, so that the very constitution of perceptions involves massive (while concise) activations of Erasmus syllogisms through the cascade of algorithmic steps being implied in according neurological processing into percepts available for consciousness. Further, rich experimental evidence with related theoretical interpretations suggest that the Weber-Fechner law, with related logarithmic conflation of input differences into output non-differences (as well as into more gross and prevailed differences), plays a key role in neurological algorithms constituting perception, and this being much so across species as well as across various senses of perception.

Viewed from an evolutionary or more neo-Darwinian perspective this massive occurrence of Erasmus syllogisms involved in perception makes much sense, due to such cognitive economy being much advantageous in survival into the fittest. If minor differences in incoming stimuli for perception do not matter much for survival, they will tend to diminish from this perspective, because the over-all capacity of the mind/brain's information processing can give more attention, with related increased attention to differences that make more of a difference with respect to issues that really matter for survival. (For theoretical discussion, see Bateson 1987, 123ff; Johansen 2008, 26-34; Johansen 2018, 232f.)

Gregory Bateson (1987, cf. also 1972, 1988) was the first to pay very serious scientific attention to Erasmus syllogisms as highly important in order to understand cognition, evolution, and culture. Bateson did not use the term "Erasmus syllogism", but alternated between the terms 'syllogisms of grass' (which is one paradigmatic case of an Erasmus syllogism) and 'metaphor'. With respect to 'metaphor' we can explain the tacitly involved Erasmus syllogism as follows: Say that 
phenomenon $a$ can be denoted metaphor for another phenomenon $b$, if and only if phenomenon $a$ stands in the same relation to a phenomenon $d$ as phenomenon $b$ stands to a phenomenon $e$. If we apply $c$ to denote location at the left side of such a relation, the metaphor then rests upon the following inference: ' $a$ is $c$; $b$ is $c$; ergo: $b$ is a' Thus, we see that application of $a$ as valid metaphor for $b$ depends upon an inference having the form of an Erasmus syllogism.

Bateson argued strongly, drawing on inter-disciplinary knowledge as well as on his own epistemology, that, despite the invalidity of 'syllogisms of grass' and 'metaphor' as judged from criteria of formal logic, these cognitive operators play a crucial role in nature, spanning from perception to more elaborate phenomena as poetry, humor, religion, and dreams:

[T] hese syllogisms are the very stuff of which natural history is made (...) all preverbal and nonverbal communication depends upon metaphor and/or syllogisms in grass (...) all verbal communication necessarily contains metaphor (...) metaphor is in fact the logic upon which the biological world has been built (Bateson 1987: 27-30).

Bateson also pointed out that even the very formulations of syllogisms of formal logic presuppose linguistic classifications of semantic entities as well as of the very categories of grammar themselves.

Today, it should not be scientifically controversial to state that creativity may emerge with catalysts of decisive inputs from ontological domains of poetry or of dreams. Even in the history of hard science we have at least some spectacular cases of such crucial emergences, as probably most strikingly illustrated by Tesla's (initial) invention of the induction motor triggered by poetry, and by Ramanujan's discovery of mathematical theorems triggered by experiences in dream space. Thus, it seems reasonable to acknowledge that innovations, major or minor, sometimes are crucially catalyzed by means of novel semantic instantiations of Erasmus syllogisms, where the details of such catalysts may have strong cultural and context dependent constraints.

We find it reasonable to comprehend the rather successful innovations and implementations proceeding the BFA-syllogism, as one such instance. In short, the paradox is: If you are not able to become seduced into some false logical reasoning, there may be something important and innovative you will not become able to achieve.

\section{Cognition, Semantics, and Translation of Boundary Objects}

Turning back to our critical remarks to Scandinavian new institutionalism, our findings may contribute to a more elaborated theory of translation processes. Our main contribution is that we provide a 
possible explanation for why certain radical innovations may occur, and that radical alteration of boundary objects should not necessarily be explained primarily by searching for coherence with institutional traits related to the context of the translators. Certainly, our empirical example could be analysed as a process of enrolment of actors during which meanings, claims and interests are inscribed in representations (cf. Latour 1987), and as a translation process enhanced by divergent interests and ideologies (cf. Latour 1987; Brunson 1987, 2000), or as a process of contextualization within a specific organizational environment (cf. Czarniawska and Joerges 1996). However, we have chosen to address aspects of the form of the representations of the future organization (seen as a boundary object), with related consequences for local interpretations. More specifically, the resemblance of the use of the term "team" in both representations (BOI and BFA) seems to contribute to equivocation (and fallacy of four terms). Further, the lack of familiarity with the semantic content of the terms used in the representations, combined with cognitive logical bias in the form of Erasmus syllogisms, seems, in our present case, to enhance radical innovation in terms of alteration of both form and meaning.

\section{Conclusion}

Our analysis demonstrates that specific characteristics of objects (forms, signs) used to represent ideas, in interplay with rather hard-wired aspects and constraints in human cognitive capabilities making certain logical fallacies rather unavoidable, may contribute to merging of concepts and rather radical alteration of objects and ideas. As a tentative generalization from this demonstration we suggest that studies of diffusions in management theories, as well as most analyses of knowledge sharing, learning and innovation processes between or within organizations, may profit from more systematic analysis of objects (forms, signs) used for representing meaning and involved cognition processes, in order to better understand outcomes of specific translation processes.

Performances of valid logical reasoning, for most persons, and especially when logical relations between structural forms turn more complex, depend much on semantic contents expressing logical relations and according matching to activation of preceding cognitive schemas with some cultural flavor. Syllogisms judged as invalid by criteria of formal logics, while not recognized as invalid by main actors, may in some contexts prove crucial, fruitful, and productive in order to achieve significant innovations. The paper has sought to account for one such case, where the non-logical endorsement of a certain invalid deadweighted Erasmus syllogism proved to be constructive in order to create and implement certain adequate and potent innovations. Thus, despite 
logical reasoning being preferable when other things are considered equal, there may occur interesting exceptions from the rule, where collective endorsement to non-logical operators may even prove necessary for innovation and implementation of certain creative actions.

\section{References}

Bateson G. 1972. Steps to an Ecology of Mind. Chicago: University of Chicago Press.

Bateson G. 1988 [1979]. Mind and Nature. A Necessary Unity. NewYork: Bantam.

Bateson G. 1987. Angels Fear. Towards an Epistemology of the Sacred. New York: Macmillan.

Brunsson, N. 2000. The Irrational Organization: Irrationality as a Basis for Organizational Action and Change. Bergen: Fagbokforlaget.

Brunsson, N. 1989. The organization of hypocrisy: Talk, decisions and actions in organizations. New York: John Wiley \& Sons.

Brunsson, N. 1986. Organizing for inconsistencies: On organizational conflict, depression and hypocrisy as substitutes for action. Scandinavian Journal of Management Studies. 2 (3-4):165-185.

https://doi.org/10.1016/0281-7527(86)90014-9

Bye R.J. 2010. Endring som læring: En studie av innføringen av SAP og nye arbeidsprosesser i Statoils BRA-prosjekt. PhD thesis 2010 (129).

Trondheim: NTNU.

Chambers, R. 2006. Participatory mapping and geographic information systems: Whose map? Who is empowered and who disempowered? Who gains and who loses? The Electronic Journal of Information Systems in Developing Countries 251:1-11. https://doi.org/10.1002/i.16814835.2006.tb00163.x

Churchland, P.S. 1986. Neurophilosophy. Toward a Unified Science of the Mind-Bran. Cambridge, Massachusetts: MIT Press.

Cohen, M.D., March, J.G. \& Olsen, J.P. 1972. A Garbage Can Model of Organizational Choice. Administrative Science Quarterly. 17 (1):1-25. https://doi.org/10.2307/2392088

Czarniawska-Joerges, B. 2007. Shadowing: and other techniques for doing fieldwork in modern societies. Copenhagen: Copenhagen Business School Press DK.

Czarniawska, B. 2001. Anthropology and organizational learning. In M. Dierkes et al. (eds.) Handbook of Organizational Learning and Knowledge, pp.118-136. Oxford: Oxford University Press. 
Czarniawska, B. \& Joerges, B. 1996. Travels of ideas. In Czarniawska, B. \& G. Sevón (Eds.), Translating Organizational Change. Berlin: Walter de Gruyter. https://doi.org/10.1515/9783110879735.13

Czarniawska, B. \& G. Sevón 2005. Translation is a vehicle, imitation its motor, and fashion sits at the wheel. In B. Czarniawska \& G. Sevón (eds.) Global ideas: how ideas, objects and practices travel in a global economy (Vol. 13). Copenhagen: Copenhagen Business School Press. https://doi.org/10.2189/asqu.51.3.512

D’Andrade, R. 1989. Culturally Based Reasoning. In A.R.H. Gellatly, D. Rogers \& J.A. Sloboda (eds.) Cognitions and Social Worlds. Oxford: Clarendon Press.

D’Andrade, R. 1992. "Cognitive Anthropology." In T. Schwartz, G.M. White and C.A. Lutz (eds.) New directions in psychological anthropology. Cambridge: Cambridge University Press.

D'Andrade, R.G. 1995. The development of cognitive anthropology. Cambridge: Cambridge University Press.

Davenport, T.H. 1993. Process Innovation. Reengineering Work through Information Technology. Boston: Harvard Business School Press.

Davenport, T.H. 1993. Process Innovation. Reengineering Work through Information Technology. Boston: Harvard Business School Press.

Deming, W. E. 1982. Out of the Crisis. Cambridge: MIT Press.

Deming, W.E. \& D.W. Edwards 1982. Quality, productivity, and competitive position (Vol. 183). Cambridge, Massachusetts: Center for advanced engineering study, MIT.

DiMaggio, P.J. and W.W. Powell 1983. The iron cage revisited: Institutional isomorphism and collective rationality in organizational fields. American Sociological Review. 48 (2): 147-160. https://doi.org/10.2307/2095101

Emery, F. \& E. Thorsrud 1976. Democracy at work: The report of the Norwegian industrial democracy program (Vol. 2). Dordrecht: Springer.

Gondhalekar, S., A. Subash Babu \& N.B. Godrej 1995. „Towards TQM using kaizen process dynamics: a case study." International Journal of Quality \& Reliability Management, 12 (9):192-209. https://doi.org/10.1108/02656719510101286

Greenwood, D.J. and M. Levin 1998. Introduction to action research. Social research for social change. Thousand Oaks: Sage Publication.

Hackman, J.R. 1986. The psychology of self-management in organizations. In M.S. Pallack \& R.O. Perloff (eds.) Psychology and Work: Productivity, change, and employment. Washington DC: American Psychological Association. https://doi.org/10.1037/10055-003

Hammer, M. 1990. Reengineering Work: Don't Automate, Obliterate. 
Harvard Business Review 64 (4):104-113.

Hammer, M. 1996. Beyond reengineering. How the process-centred organization is changing our works and our lives. London: Harper Collins Publishers.

Hammer, M. and J. Champy 1993. Reengineering the Corporation. New York: Harper Collins.

Herbst, P.G. 1976. Alternatives to hierarchies. International series on the quality of working life; vol. 2. Leiden: Martinus Nijhoff Social Sciences Division.

Holberg, Ludvig 1967 [1723]. Erasmus Montanus eller Rasmus Berg. Oslo: Gyldendal.

Johansen, S.E. 2018. Systematic Unfoldment of Differential Ontology from Qualitative Concept of Information. In: C. Thomas (ed.): Ontology in Information Science, ch. 10:225-254. InTechOpen.

https://doi.org/10.5772/intechopen.72951

Johansen S.E. 2008. Grunnriss av en differensiell epistemologi. 2nd ed. Oslo: Abstrakt. (English translation from Norwegian in transit: Outline of Differential Epistemology.)

Kahneman, D., Slovic, S. P., Slovic, P., and Tversky, A. (eds.) 1982.

Judgment under uncertainty: Heuristics and biases. Cambridge: Cambridge University Press. https://doi.org/10.1017/cbo9780511809477

Latour, B. 1987. Science in action: How to follow scientists and engineers through society. Boston: Harvard University Press.

Lundberg, K. G., and Sataøen, H. L. 2014. Institusjonell etnografi: Ei inspirasjonskjelde for den skandinaviske organisasjonsteorien? Nordiske organisasjonsstudier. 16 (1):30-50.

Mandler, J.M. 1984. Stories, Scripts, and Scenes. Aspects of Schema Theory. New York: Psychology Press.

March, J.G. 1994: A Primer on Decision Making. New York: The Free Press. Manz, C.C. 1992. Self-leadership... the heart of empowerment. The Journal for Quality and Participation. 15 (4): 80.

Meyer, J.W. and R. Rowan 1977. Institutionalized organizations: Formal structures as myth and ceremony. American journal of Sociology. 83 (2):340-363. https://doi.org/10.1086/226550

Rosch, E. 1983. Prototype Classification and Logical Classification: The Two Systems. In E.K. Scholnick (ed.) New Trends in Conceptual Representation: Challenges to Piaget's Theory?, pp. 73-86. Hillsdale: Lawrence Erlbaum Associates.

Røvik K.A. 2002. The Secrets of the Winners: Management Ideas that Flow. In K. Sahlin-Andersson and L. Engwall. (eds.) The expansion of 
management knowledge: Carriers, flows, and sources. Stanford: Stanford University Press.

Røvik, K.A. 2011. From fashion to virus: An alternative theory of organizations' handling of management ideas. Organization Studies. 32 (5):631-653. https://doi.org/10.1177/0170840611405426

Røvik, K. A. 2016. Knowledge transfer as translation: Review and elements of an instrumental theory. International Journal of Management Reviews. 18 (3):290-310. https://doi.org/10.1111/ijmr.12097

Simon, H.A. 1955. A behavioral model of rational choice. The quarterly journal of economics 69 (1): 99-118.

Scott, W.R. 1995. Institutions and organizations. Ideas, Interests, and Identities. Los Angeles: SAGE.

Star, S.L. 1988. The structure of ill-structured solutions: Boundary objects and heterogeneous distributed problem solving. In M. Huhns \& L. Gasser (eds.) Readings in distributed artificial intelligence. Menlo Park, CA: Kaufman. https://doi.org/10.1016/b978-1-55860-092-8.50006-x

Star, S.L. 2010. This is not a boundary object: Reflections on the origin of a concept. Science, Technology, \& Human Values. 35 (5):601-617. https://doi.org/10.1177/0162243910377624

Star, S.L. and J.R. Griesemer 1989. Institutional ecology, 'translations' and boundary objects: Amateurs and professionals in Berkeley's Museum of Vertebrate Zoology, 1907-39. Social studies of science. 19 (3):387-420. https://doi.org/10.1177/030631289019003001

Suárez-Barraza, M.F. and T. Lingham 2008. Kaizen within kaizen teams: continuous and process improvements in a Spanish municipality. Asian Journal on Quality. 9 (1):1-21. https://doi.org/10.1108/15982688200800001

Trist, E.L. 1976. Critique of scientific management in terms of sociotechnical theory. In M. Weir (ed.) Job Satisfaction, pp.81-90. London: Fontana.

Tversky, A. and Kahneman, D. 1982. Judgments of and by representativeness. In D. Kahneman, P. Slovic, and A. Tversky (eds.) Judgment under uncertainty: Heuristics and biases, 84-98. Cambridge: Cambridge University Press. https://doi.org/10.1017/cbo9780511809477.007

Tversky, A. and Kahneman, D. 1983. Extensional versus intuitive reasoning: The conjunction fallacy in probability judgment. Psychological Review 90: 293-315. https://doi.org/10.1037/0033-295x.90.4.293

Wason, P.C. 1968. Reasoning about a Rule. Quarterly Journal of Experimental Psychology 20: 73-281.

Wenger, E. 1998. Communities of practice: Learning, meaning, and identity. 
Cambridge: Cambridge University Press.

Wæraas, A. and Nielsen, J. A. 2016. Translation theory 'translated': Three perspectives on translation in organizational research. International Journal of Management Reviews, 18 (3): 236-270. https://doi.org/10.1111/ijmr.12092

Rolf Johan Bye is senior researcher at SINTEF Digital, Norway and associated with Department of social anthropology at Norwegian University of Technology and Science. He holds a PhD in sociology and a $\mathrm{PhD}$ (Norwegian 'magistergrad') in social anthropology. His main areas of research are processes of organizational change, organizational learning, work practices, organizational safety, and related applications of management theories. He has been involved in several research project within organizations in various industries (including oil and gas, aviation, shipping, and chemical industry) and various countries (including Norway, UK, Hungary, Oman, and China). Corresponding author: rolf.johan.bye@sintef.no.

Stein Erik Johansen is full professor in social anthropology at Norwegian University of Technology and Science, and adjunct professor at Division of Physics, Institute for Basic Research, Florida, USA. He holds a D.Sc. (classical Norwegian dr. philos.) in economics (1991) and a PhD (Norwegian 'magistergrad') in philosophy (1985). He has received the Santilli-Galilei Award (Gold Medal and Prize 2008) from Santilli-Galilei Academy " in honour of contributions to natural philosophy", and the SIPS Scientific Award (2016) to scientists having "achieved notable contribution in mathematical sciences" - "for unprecedented advances in the Fibonacci numbers". His main areas of research have been within economic theory and anthropology, number theory, complexity and system theory, epistemology/ontology, and cognitive anthropology. 